\title{
CONTABILIDADE PARA USUÁRIOS EXTERNOS: UMA ANÁLISE DA PRODUÇÃO CIENTÍFICA BRASILEIRA À LUZ DO CONGRESSO ANPCONT DE 2007 A 2016
}

\author{
ACCOUNTING FOR EXTERNAL USERS: AN ANALYSIS OF \\ BRAZILIAN SCIENTIFIC PRODUCTION IN LIGHT OF THE \\ ANPCONT CONGRESS FROM 2007 TO 2016
}

\section{CONTABILIDAD PARA USUARIOS EXTERNOS: ANÁLISIS DE LA PRODUCCIÓN CIENTÍFICA BRASILEÑA A LA LUZ DEL CONGRESO ANPCONT DESDE 2007 HASTA 2016}

Henrique César Melo Ribeiro

Professor Adjunto da Universidade Federal do Piauí (UFPI), Brasil / Doutor em Administração de Empresas pela Universidade Nove de Julho hcmribeiro@gmail.com

\author{
Contextus \\ ISSNe 2178-9258 \\ Organização: Comitê Científico Interinstitucional \\ Editor Científico: Carlos Adriano Santos Gomes \\ Avaliação: double blind review pelo SEER/OJS \\ Edição de texto e de layout: Carlos Daniel Andrade \\ Recebido em 19/04/2017 \\ Aceito em 02/10/2017 \\ $2^{a}$ versão aceita em 03/10/2017
}

\section{RESUMO}

O objetivo deste estudo foi investigar o perfil das publicações relacionadas à contabilidade para usuários externos divulgadas, de 2007 a 2016, nos congressos da Associação Nacional de Programas de Pós-Graduação em Ciências Contábeis (ANPCONT). Metodologicamente, a pesquisa utilizou as técnicas de análise bibliométrica e sociométrica. Dentre os principais achados, constatou-se que Fernando Dal-Ri Murcia, Marcelo Alvaro da Silva Macedo e Roberto Carlos Klann foram os autores mais profícuos. As instituições mais produtivas foram: USP, Fucape, UFPB, FURB, UFC e UFRJ. Observou-se pouca densidade e, ao mesmo tempo, alta centralidade de grau e de intermediação nas redes de coautoria e das instituições. Os temas mais publicados foram: gerenciamento de resultados, normas internacionais de contabilidade, disclosure, governança corporativa, informação contábil, investimento, auditoria, disclosure voluntário, gestão pública e disclosure ambiental.

Palavras-chave: Contabilidade para usuários externos; Produção científica; ANPCONT; Bibliometria; Sociometria.

\begin{abstract}
This study aimed to investigate the profile of the works presented at the National Association of Accountancy Graduate Programs (ANPCONT) congresses from 2007 to 2016 that were related to accounting for external users. Methodologically, the research used the techniques of bibliometric and sociometric analyses. Among the main findings, Fernando Dal-Ri Murcia, Marcelo Alvaro da Silva Macedo and Roberto Carlos Klann turned out to be the most prolific authors. The most productive institutions were: USP, Fucape, UFPB, FURB, UFC and UFRJ. Low density and, at the same time, a high level of degree centrality and of intermediation centrality were observed in co-authorship networks and institutions. The most published
\end{abstract}


topics were: result-oriented management, international accounting standards, disclosure, corporate governance, accounting information, investment, auditing, voluntary disclosure, public management and environmental disclosure.

Keywords: Accounting for external users; Scientific production; ANPCONT; Bibliometrics; Sociometry.

\section{RESUMEN}

El objetivo de este estudio fue investigar el perfil de publicaciones relacionadas con la contabilidad para usuarios externos reportadas, desde 2007 hasta 2016, en los congresos de la Asociación Nacional de Programas de Posgrado en Ciencias Contables (ANPCONT). En cuanto a la metodología, la investigación utilizó las técnicas de análisis bibliométrico y sociométrico. Entre los principales resultados, Fernando Dal-Ri Murcia, Marcelo y Álvaro da Silva Macedo Roberto Carlos Klann se mostraron como los autores más fecundos. Las instituciones más productivas fueron USP, FUCAPE, UFPB, FURB, UFC y UFRJ. Hubo poca densidad y, al mismo tiempo, alta centralidad de grado y de intermediación en las redes e instituciones de coautoría. Los temas más publicados fueron: gestión de los resultados, normas internacionales de contabilidad, divulgación, gobierno corporativo, información contable, inversión, auditoría, revelación voluntaria, gobernabilidad y divulgación ambiental.

Palabras clave: Contabilidad para los usuarios externos; Producción científica; ANPCONT; Bibliometría; Sociometría.

\section{INTRODUÇÃ̃O}

Qualquer campo do saber científico ganha com a análise de sua produção, uma vez que esta permite, por exemplo, discernir entre temas já estudados e aqueles em necessidade de maior atenção (NORONHA et al., 2006). Nesse sentido, a análise da produção científica influencia a construção e reconstrução das áreas do conhecimento (RÖDER; SILVA, 2013) e revela-se um mecanismo para mensuração (SANTOS, 2003), incluindo a criação de indicadores de acompanhamento das publicações. Além disso, é uma ferramenta estratégica para fortalecer e difundir iniciativas de parceria (GOMES; CAVALCANTE; LINS, 2016), quer de autores entre si, quer entre suas respectivas instituições (SOUZA et al., 2008; RIBEIRO, 2017).

Normalmente, o caminho da produção acadêmica é a submissão a eventos científicos, como congressos e seminários, seguida da publicação e posterior apresentação. Logo após ajustes decorrentes de contribuições recebidas nos eventos, a pesquisa é submetida à avaliação e, por conseguinte, à publicação dita definitiva, em periódicos científicos. Salienta-se a relevância de tais procedimentos, pois é só com a divulgação - nos canais formais de comunicação (periódicos) e/ou informais (eventos) - que os resultados do estudo ganham envergadura e passam a existir plenamente (ANJOS et al., 2015). No caso particular dos encontros acadêmicos, os 
pesquisadores já têm a oportunidade de discutir e socializar seus respectivos estudos, contribuindo com isso para o avanço da área do conhecimento (MACHADO et al., 2009).

Em suma, a produção científica consiste na maneira de os estudiosos comunicarem suas pesquisas e resultados à sociedade acadêmica e interessados; e os eventos/congressos científicos, em uma forma de trocar informações e conhecimentos em processo de desenvolvimento. Ali se esclarecem dúvidas e aperfeiçoam métodos mediante o debate de ideias. Com isso, os congressos se mostram como um estágio do aperfeiçoamento de estudos, a serem apurados e levados a futuras publicações (MATOS et al., 2012).

Dentre esses eventos, destaca-se o da Associação Nacional de Programas de Pós-Graduação em Ciências Contábeis (ANPCONT), criada pelos coordenadores dos programas recomendados pela Coordenação de Aperfeiçoamento de Pessoal de Nível Superior (CAPES) em 2006, com o objetivo de atuar na área de educação, incorporando e representando as instituições de ensino superior (IESs) brasileiras que mantêm cursos de mestrado e/ou doutorado em Ciências Contábeis (DIAS; NETO; BARBOSA, 2010).
A comunicação da produção científica em contabilidade é imprescindível (SOUZA et al., 2008), influenciando no conhecimento do perfil e nas condutas acadêmicas dos pesquisadores da área (BORGES; FARIA; GIL, 2007). Dentre as áreas temáticas que vêm se destacando nas publicações científicas em contabilidade, está a de "contabilidade para usuários externos" (BARBOSA et al., 2014; COSTA; MARTINS, 2016; FREZATTI, 2017), que envolve identificação, aferição e evidenciação da informação contábil e tem interseções, sobretudo, com as seguintes outras áreas: teoria da contabilidade, contabilidade societária, contabilidade internacional, responsabilidade socioambiental, capital intelectual, análise das demonstrações financeiras, dentre outros temas (ANPCONT, 2017).

Diante desse pano de fundo, contempla-se a questão que norteará o presente estudo: quais o perfil e o comportamento das publicações relacionadas à contabilidade para usuários externos divulgada nos congressos da ANPCONT de 2007 a 2016? Assim, o objetivo da pesquisa é investigar o perfil e o comportamento das publicações, relacionadas àquela área temática, divulgadas nas edições de 2007 a 2016 do congresso ANPCONT. Reitera-se a 
importância desta pesquisa, em virtude de ela evidenciar dados e informações contemporâneas, oriundas de indicadores bibliométricos e sociométricos, e contribuir assim para potencializar o entendimento e a compreensão da área temática objeto de estudo.

A bibliometria concentra-se na produção científica mediante o estudo quantitativo das publicações, tendo como principal objetivo desenvolver e aferir indicadores (RAVELLI et al., 2009). Quanto à análise sociométrica, ou seja, voltada para redes sociais (no sentido tradicional, mais abrangente que o digital), busca identificar diversos aspectos de técnicas colaborativas tais como grupos de estudo, pesquisadores líderes, IESs mais atuantes, entre outras possibilidades (MACHADO JUNIOR; SOUZA; PARISOTTO, 2014).

Observando a literatura acadêmica nacional, foram encontrados e verificados somente dois trabalhos específicos sobre contabilidade para usuários externos: Coelho; Soutes; Martins (2010) e Silva; Wanderley; Santos (2010). Tal constatação soma-se à justificativa de investigar a produção acadêmica nacional da mencionada área no âmbito do ANPCONT.

De maneira geral, este trabalho contribui para entender as nuances da área temática em seu bojo, enfatizando informações de 10 anos de suas publicações no congresso ANPCONT e evidenciando: os atores (autores e IESs) mais profícuos, suas respectivas redes sociais e os temas abordados. Por conseguinte, tornar-se-á disponível para pesquisadores mais experientes $\mathrm{e}$, sobretudo, para as mais novos um acervo capaz de gerar insights e valor acadêmico, possivelmente redundando na criação ou no aperfeiçoamento de outros estudos em Ciências Contábeis no Brasil.

\section{FUNDAMENTAÇÃO TEÓRICA}

\subsection{Contabilidade para Usuários Externos}

A contabilidade empresarial possui diversos usuários externos, tais como: os acionistas, os gestores de fundos de investimento, os órgãos que representam o governo, os credores, dentre outros (FREZATTI; AGUIAR; GUERREIRO, 2007). A contabilidade para usuários externos permite testes mais alargados acerca das práticas contábeis desenvolvidas ao longo de uma série histórica (BRUGNI et al., 2012), repercutindo sobre a responsabilidade das organizações ao representar determinado panorama na forma de demonstrações contábeis. A maneira como estas são 
criadas e analisadas impactam diretamente na organização (ASSUNÇÃO, 2011).

No panorama acadêmico, a contabilidade para usuários externos costuma ser tratada em publicações relacionadas aos aspectos de identificação, aferição e evidenciação da informação contábil, nas áreas de teoria da contabilidade, contabilidade societária, contabilidade internacional, balanço social, contabilidade pública, contabilidade tributária e análise das demonstrações financeiras etc. (MATOS et al., 2012). A literatura acadêmica nacional mostra a representatividade da contabilidade para usuários externos (CRUZ; FERREIRA; SZUSTER, 2011) em dissertações (SANTOS; KLANN; RAUSCH, 2011), em teses (BONFIM, 2013), em periódicos (LIMA; DINIZ; SILVA， 2013), em congressos como o da ANPCONT (BARBOSA; BARROS, 2010; COSENZA et al., 2016) e o da USP de Controladoria e Contabilidade (AMARAL et al., 2014; CRUZ et al., 2011) e, por conseguinte, em programas de pós-graduação em Contabilidade (MARTINS; LUCENA, 2014).

Contudo, encontraram-se apenas dois estudos que, de maneira mais específica, manifestaram dados e informações sobre a área temática: Coelho, Soutes e Martins (2010) e Silva,
Wanderley e Santos (2010). Os autores da primeira publicação levantaram as características das abordagens metodológicas empregadas em trabalhos apresentados nos encontros de 2005 e 2006 da ANPAD. Predominaram, segundo eles, artigos que examinaram as demonstrações contábeis e se originaram de apenas quatro universidades: USP, Fucape, UnB e UPM. Por sua vez, os autores da segunda publicação analisaram o emprego da metodologia estatística nos trabalhos científicos apresentados no congresso da ANPCONT, no congresso USP de Controladoria e Contabilidade e no EnANPAD de 2007 a 2009. Observaram que mais de $50 \%$ dos artigos utilizaram abordagem estatística, com a incidência aumentando no decorrer dos anos. As universidades do sudeste do país foram as que mais contribuíram com artigos contendo essa abordagem, destacando-se a USP e a Fucape.

Tanto Coelho, Soutes e Martins (2010), quanto Silva, Wanderley e Santos (2010) debruçaram-se sobre eventos científicos, nas áreas de administração ou contabilidade. E ambas as publicações colocaram em evidência informações relevantes como, por exemplo, o fato de a USP e a Fucape serem as mais representativas no que se refere a produção científica na área temática em questão. 
Contudo, ambos os estudos apresentaram informações já com algum tempo de divulgação. $\mathrm{O}$ presente estudo, em contrapartida, alargará e complementará os resultados já obtidos ao contemplar estudos mais contemporâneos.

\subsection{Bibliometria e rede social}

A técnica de análise bibliométrica volta-se para aspectos quantitativos da produção, disseminação e uso da informação divulgada (RAVELLI et al., 2009), sendo, portanto, ferramenta primordial para analisar a produção científica, com base em indicadores próprios (RIBEIRO; SANTOS, 2015). Isso não nega que, "como parte importante do processo de compreensão da ciência, a análise bibliométrica deve ser acompanhada de pesquisas qualitativas para que os seus resultados possam ser interpretados em sua abrangência" (CARDOSO, 2005, p. 35). Seja como for, uma boa análise abrange a bibliometria, que se pauta pelas chamadas leis de Lotka, Bradford e Zipf (RIBEIRO, 2016).

A Lei de Lotka mensura a produtividade dos autores, e a Lei de Bradford mensura a representatividade das revistas. A Lei de Zipf, por sua vez, afere a frequência das palavras-chave nos textos (SILVA; BEUREN, 2015). Neste estudo, será usada somente a Lei de Lotka como embasamento e melhor entendimento da proficuidade dos autores e, consequentemente de suas respectivas envergaduras na produção acadêmica.

A rede social é entendida como um conjunto de dois atores, que podem ser indivíduos, instituições ou grupos. Suas relações (laços) sociais, que dependem de uma interação já estabelecida entre os atores (BRANDÃO; BALDI; ALBAN, 2014), divulgam condutas, costumes, prioridades, informações, conhecimentos e saberes (ESTRELLA; BATAGLIA, 2013).

Um conjunto de redes sociais se caracterizam por sua densidade e sua centralidade (WALTER; BACHL; BARBOSA, 2012). A densidade consiste em uma medida de intensidade da interação dos atores da rede social. Sua aferição contribui para a formulação de conjecturas sobre as informações e os conhecimentos que norteiam a rede (MELLO; CRUBELLATE; ROSSONI, 2010). A centralidade diz respeito aos atores mais representativos e importantes na rede (NASCIMENTO; BEUREN, 2011).

Existem diversas proxies que servem para mensurar a centralidade. As mais habitualmente usadas são: (a) centralidade de grau (degree); e a (b) centralidade de intermediação 
(betweenness) (MENDES-DA-SILVA; ONUSIC; GIGLIO, 2013). A centralidade de grau se baseia no número de conexões diretas que um ator possui, enquanto a de centralidade de intermediação define se determinado ator assume ou não posição de intermediador na rede social (CRUZ et al., 2011).

Diante do contexto, realça-se que a bibliometria e a sociometria (redes sociais) (WALTER; BACHL; BARBOSA，2012) são de grande valia para alcançar uma melhor compreensão sobre o desenvolvimento de pesquisas e a difusão de conhecimentos em determinado campo do saber, incluídas suas bases teóricas, o que consiste em um fato de avanço ou consolidação das informações e conhecimentos gerados (SANTOS et al., 2016; BRIZOLLA; CHIARELLO; LAVARDA, 2014).

\section{PROCEDIMENTOS METODOLÓGICOS}

O objetivo deste estudo foi investigar o perfil e o comportamento das publicações relacionadas à área temática contabilidade para usuários externos divulgada nos congressos ANPCONT de 2007 a 2016. Para tanto, utilizaram-se as técnicas de análise bibliométrica (CARDOSO, 2005) e sociométrica (WALTER; BACHL; BARBOSA, 2012).
Outros estudos orientados por essas técnicas foram desenvolvidos em diferentes áreas do conhecimento no Brasil: Administração (DAVEL; ALCADIPANI, 2003), Contabilidade de Custos (CARDOSO; PEREIRA; GUERREIRO, 2007), Contabilidade Gerencial (NASCIMENTO; JUNQUEIRA; MARTINS, 2010), Controladoria (BEUREN; SCHLINDWEIN; PASQUAL， 2007), Ensino e pesquisa em contabilidade (MENDONÇA NETO; $\quad$ RICCIO; SAKATA, 2009), Finanças (LEAL; ALMEIDA; BORTOLON, 2013), Turismo (BRUNELLI et al., 2010), dentre outras.

Foi feita uma coleta de dados em artigos divulgados no âmbito da Associação Nacional de Programas de PósGraduação em Ciências Contábeis (http://www.anpcont.org.br/congressosanpcont), no período de 2007 a 2016, o que corresponde a um levantamento longitudinal de 10 anos. Os artigos envolvidos foram especificamente da área temática contabilidade para usuários externos. A coleta de dados iniciou-se em março de 2017 e encerrou-se em abril de 2017.

O processo permitiu identificar 294 estudos divulgados. A análise dos dados se fundamentou nos seguintes indicadores: (I) autores; (II) redes de coautoria; (III) 
instituições; (IV) redes sociais das instituições; e (V) temas abordados. Tais indicadores foram calculados e capturados com os softwares UCINET ${ }^{\circledR} \quad 6 \quad \mathrm{e}$ NetDraw ${ }^{\circledR} 2$ for Windows e Microsoft Excel 2007. O uso destes decorre do fato de já serem legitimados em estudos publicados em revistas científicas sobre diversos temas/áreas do conhecimento: Informação (PINHEIRO; SILVA, 2008), Administração (BALESTRIN; VERSCHOORE; REYES JUNIOR, 2010); Contabilidade (FARIA et al., 2011); Turismo (SOUZA et al., 2014); Economia (SOUZA et al., 2015) e Finanças (RIBEIRO, 2017).

\section{ANÁLISE E DISCUSSÃO DOS RESULTADOS}

A Figura 1 evidencia os 536 autores identificados neste estudo, colocando em ênfase os 15 mais profícuos. Fernando DalRi Murcia, Marcelo Alvaro da Silva Macedo e Roberto Carlos Klann são os autores mais produtivos, todos com oito publicações. As pesquisas de Barbosa e Barros (2010) e de Matos et al. (2012) corroboram os achados, ao destacarem Fernando Dal-Ri Murcia como o mais profícuo. Cada um dos seguintes pesquisadores tem sete artigos divulgados: Edilson Paulo, Fábio Moraes da Costa e Márcio André Veras Machado. Com seis investigações, aparecem os acadêmicos: Adolfo Henrique Coutinho e Silva, Adriano Rodrigues, Antonio Lopo Martinez, Ariovaldo dos Santos, Clóvis Antônio Kronbauer, Maisa de Souza Ribeiro, Márcia Martins Mendes De Luca, Paulo Roberto da Cunha e Romualdo Douglas Colauto. 
Figura 1 - Autores

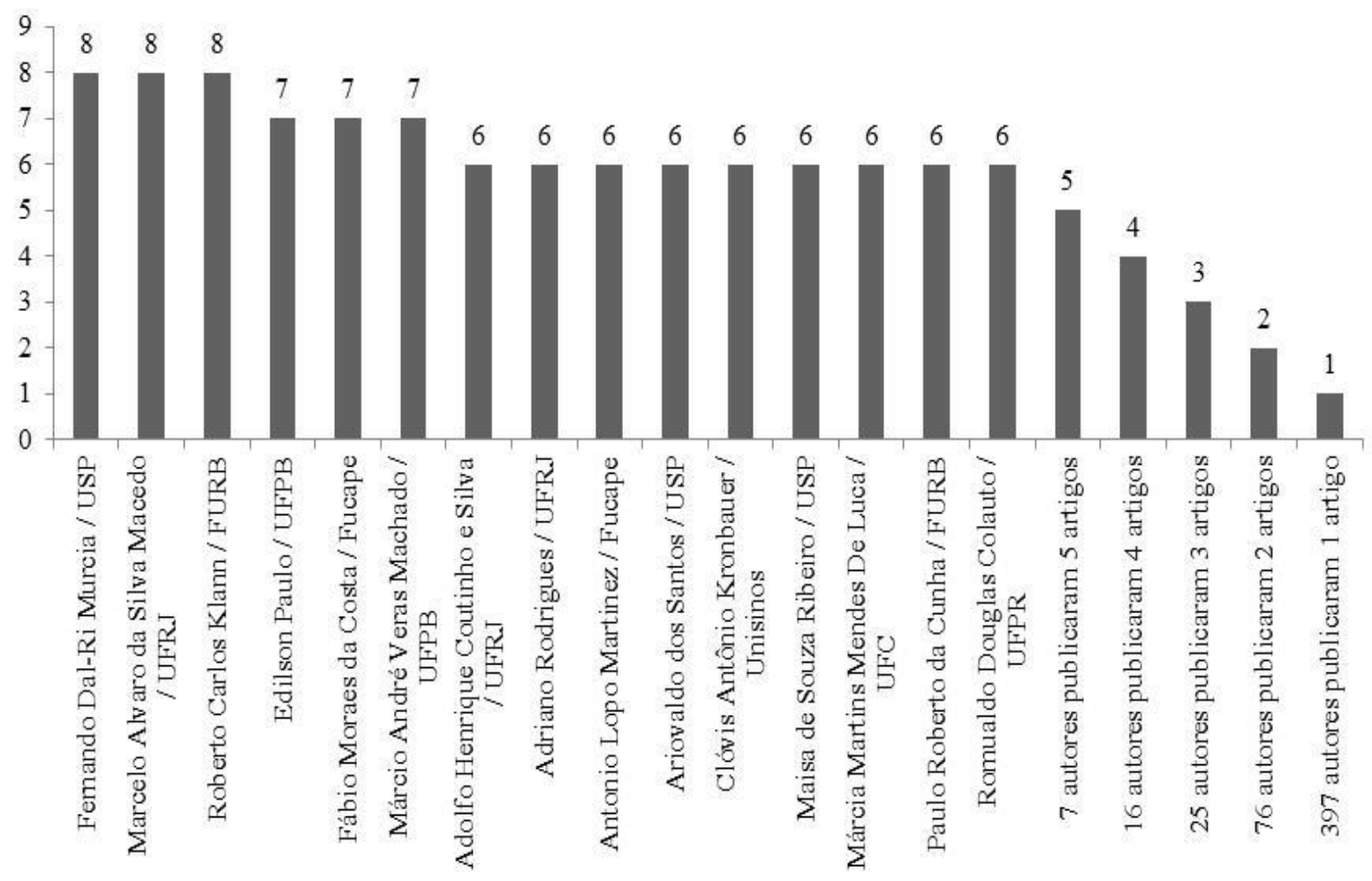

Fonte: dados da pesquisa.

De maneira geral, 15 autores publicaram de seis a oito estudos, 124 divulgaram de duas a cinco pesquisas, e a grande maioria - 397 acadêmicos contribuíram com uma investigação cada. Tais resultados vão ao encontro da Lei de Lotka, referente à produtividade dos autores (SILVA; BEUREN, 2015).

Segundo ela, poucos pesquisadores costumam publicar muito, ao passo que muitos comumente divulgam poucas pesquisas (RIBEIRO, 2017).

A Figura 2 exibe a rede de coautoria dos 536 pesquisadores identificados neste trabalho, realçando a centralidade de grau. 


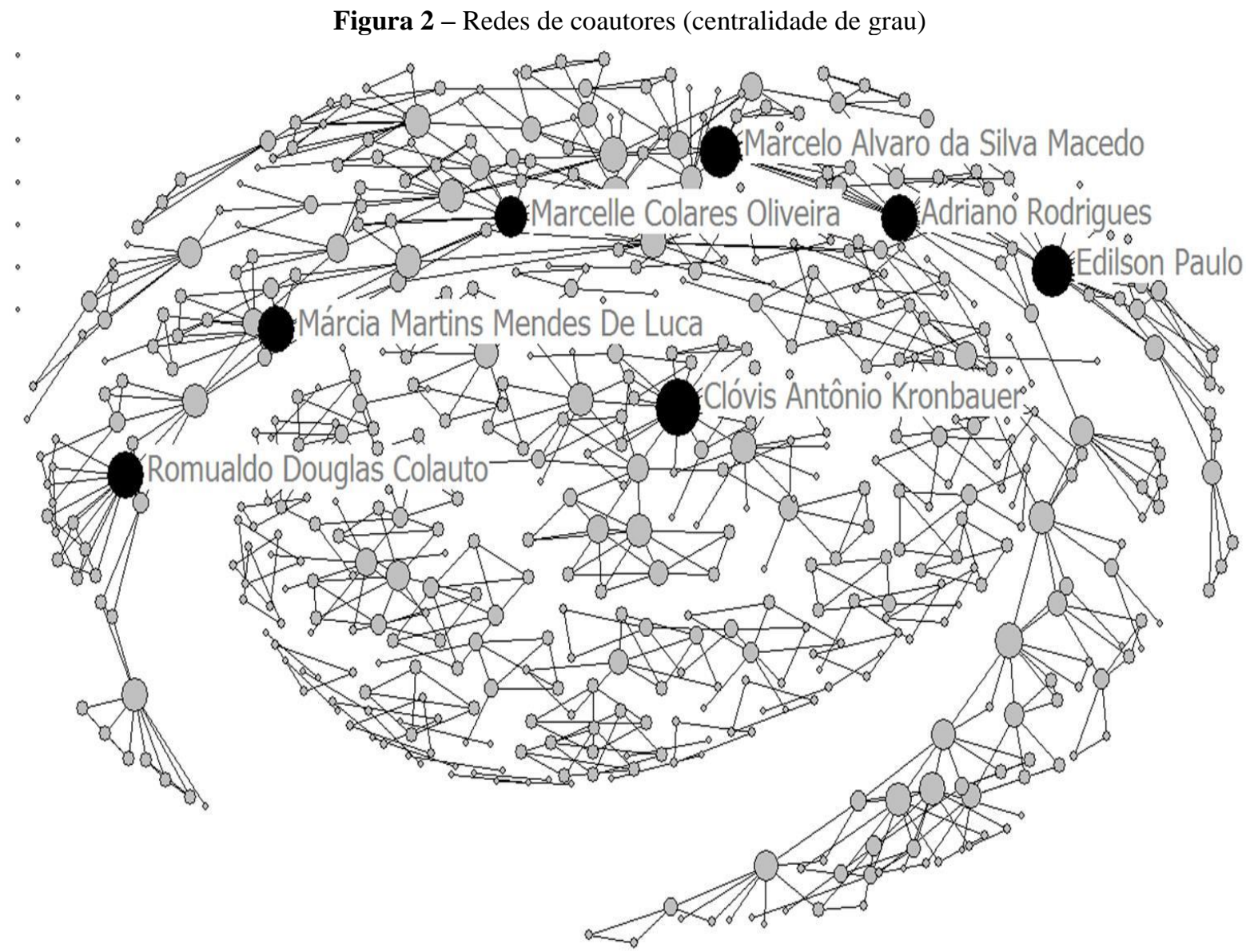

Fonte: dados da pesquisa.

A rede de coautoria tem densidade 0,0060, significando que $0,6 \%$ das interações são realizadas. Nesse caso, destacam-se Clóvis Antônio Kronbauer, Marcelo Alvaro da Silva Macedo, Edilson Paulo, Adriano Rodrigues, Márcia Martins Mendes de Luca, Romualdo Douglas Colauto e Marcelle Colares Oliveira como os mais centrais. Os seis primeiros estão entre os mais prolíferos desta pesquisa. É constatado também que os estudiosos mais centrais representam e influenciam de maneira direta na produtividade (Figura 4) e, na centralidade de grau (Figura 5) de algumas das IESs evidenciadas nesta pesquisa.

As informações esmiuçadas nesta seção contribuem para encontrar quais pesquisadores são mais representativos (CRUZ et al., 2011) e, com isso, determinantes para se conseguir agregar conhecimento e, posteriormente, difundir e disseminar na literatura acadêmica nacional informações valiosas no que se refere à temática ora investigada. A Figura 3, corrobora e complementa a Figura 2 ao manifestar em seu escopo a centralidade de intermediação. 
Figura 3 - Redes de coautores (centralidade de intermediação)



Fonte: dados da pesquisa

Em se tratando da centralidade de intermediação, realçam-se os autores: Alexsandro Broedel Lopes, Fernando DalRi Murcia, Marcelo Alvaro da Silva Macedo, Aridelmo José Campanharo Teixeira, Adriano Rodrigues, Ariovaldo dos Santos e Adolfo Henrique Coutinho e Silva. Destes, cinco estão entre os mais profícuos, dos quais somente dois, por sua, ficam em evidência também na centralidade de grau: Marcelo Alvaro da Silva Macedo e Adriano Rodrigues. Com isso, é coerente e salutar afirmar que os estudiosos por último citados são os de maior envergadura, no que se refere a produtividade, bem como a centralidades de grau e de intermediação, tendo o poder de interagir com maior pujança com os demais autores da rede. Assim, podem influenciar de maneira direta e/ou indireta as produções e agregar valor científico.

A Figura 4 exibe as 76 IESs identificadas neste trabalho, ressaltando as 15 mais produtivas. 
Figura 4 - Instituições



Fonte: dados da pesquisa.

A USP surge como a instituição mais profícua, com 70 artigos publicados. Em seguida, aparece a Fucape, com 40 divulgações. Corroboram estes achados as investigações de Coelho, Soutes e Martins (2010) e Silva, Wanderley e Santos (2010). Outros estudos análogos também vão ao encontro dos resultados: Souza et al. (2008), Matos et al. (2012) e Amaral et al. (2014). Enfatizam-se também as IESs: UFPB (com 29 publicações), FURB (22 publicações), UFC e UFRJ (ambas com 19 investigações), UFSC (16), Unisinos (15), UFPR e UFU (ambas com 12), UnB e UFMG (ambas com 11), UFPE (10), UPM (oito) e UERJ (com sete estudos).

Em suma, 15 IESs publicaram de sete a 70 artigos; 19 instituições divulgaram de dois a 6 papers, e a grande maioria - 42 IESs - evidenciaram um trabalho cada, equivalendo a aproximadamente $55 \%$ do total de instituições identificadas nesta pesquisa. Os achados vislumbrados nesta seção contribuem para verificar e constatar as instituições mais representativas no panorama acadêmico da área temática objeto de estudo. Tais IESs são essenciais para difundir e socializar as informações e o conhecimento sobre a área.

A Figura 5 permite visualizar a rede de colaboração das 76 IESs identificadas nesta pesquisa, enfatizando a centralidade de grau delas. Com uma densidade de $0,0421(4,21 \%$ das interações), a rede social das IESs apresenta a USP, a UFPB, a Unisinos e a UFRJ como as mais centrais, ou seja, com maior degree (MENDES-DA-SILVA;

ONUSIC; GIGLIO, 2013). Convém salientar que, dessas instituições em destaque, todas estão entre as mais produtivas. 
Figura 5 - Rede social das instituições (centralidade de grau)

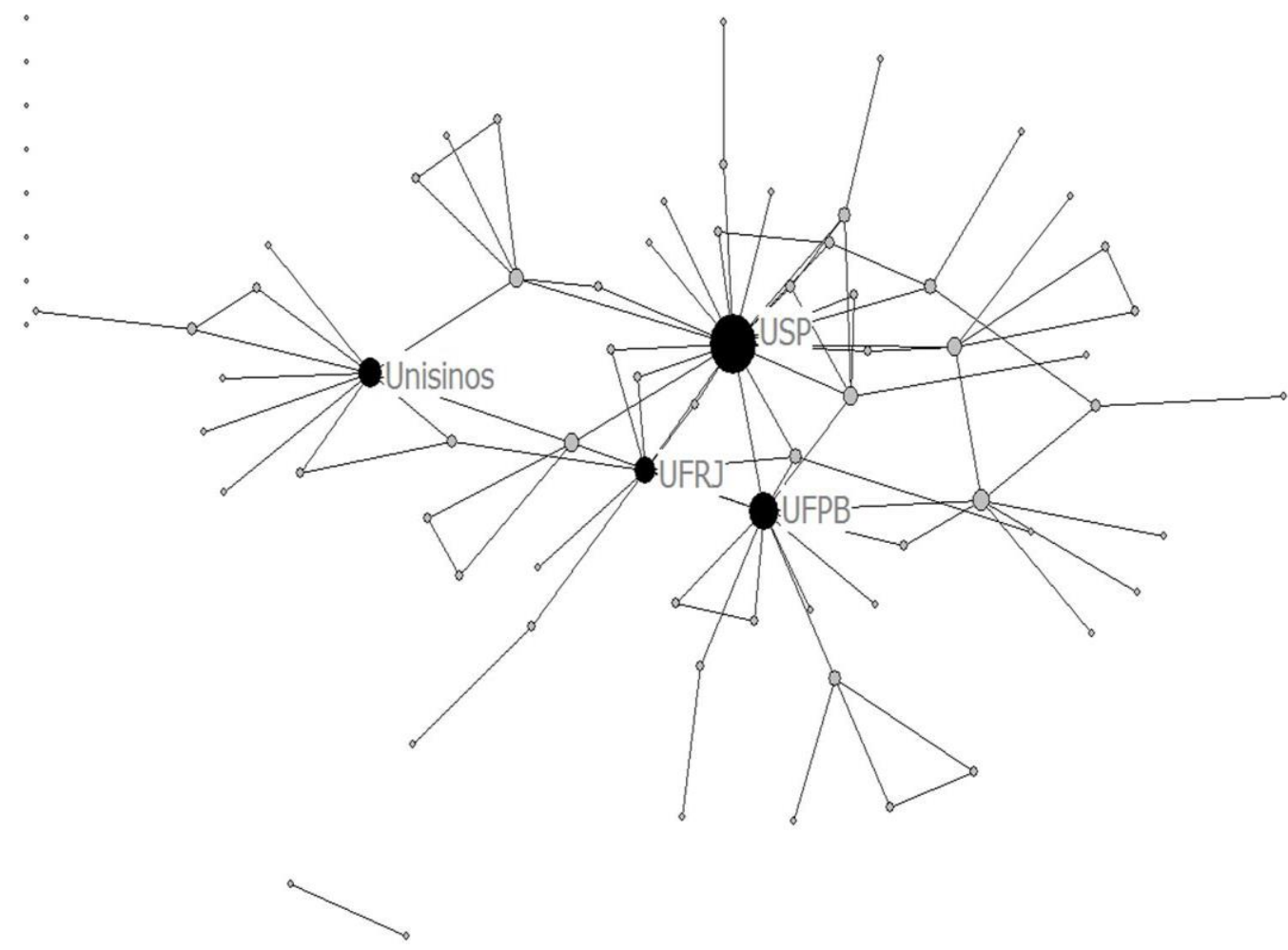

Fonte: dados da pesquisa.

A Figura 6 complementa e corrobora a Figura 5, ao enfocar a centralidade de intermediação das IESs.

Figura 6 - Rede social das instituições (centralidade de intermediação)

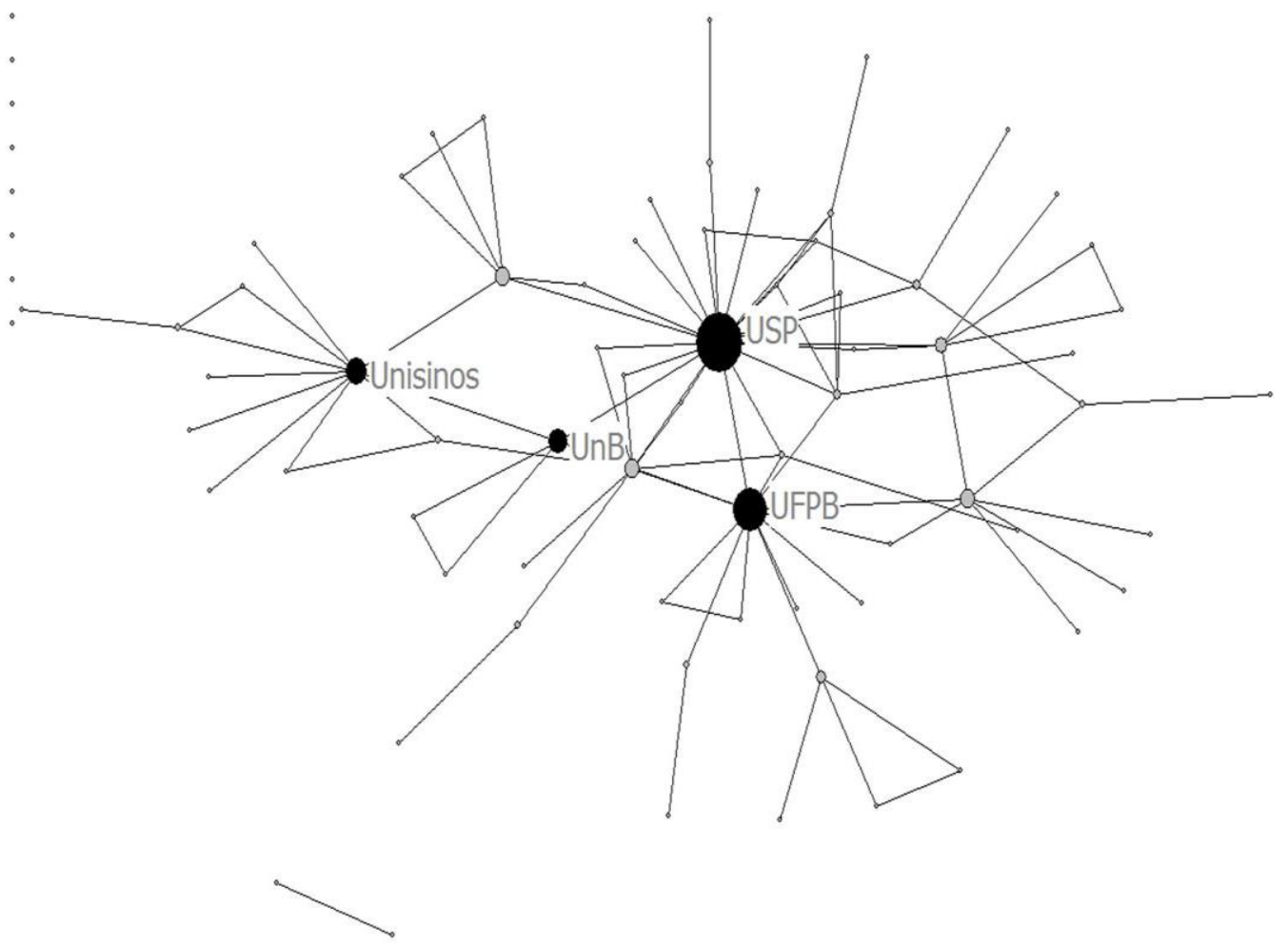

Fonte: dados da pesquisa. 
Aqui estão contempladas as IESs com maior betweenness (CRUZ et al., 2011): USP, UFPB, Unisinos e UnB.

Destas, três se destacam também no que tange ao degree e, consequentemente, à proficuidade na área temática em investigação: USP, UFPB e Unisinos. De maneira geral, pode-se dizer que estas são as instituições mais importantes e preponderantes na produção científica da área de contabilidade para usuários externos e, concomitantemente, dos temas relacionados. A Tabela 1 evidencia os 92 temas identificados e abordados nesta pesquisa, colocando em foco os 10 mais divulgados.

Tabela 1 - Temas abordados

\begin{tabular}{|c|c|c|c|c|c|c|c|c|c|c|c|c|}
\hline Ano/Temas & 07 & 08 & 09 & 10 & 11 & 12 & 13 & 14 & 15 & 16 & Total & $\%$ \\
\hline Gerenciamento de resultados & 2 & 2 & 1 & & 2 & 2 & 1 & 1 & 2 & 3 & 16 & $5,44 \%$ \\
\hline Normas Internacionais de Contabilidade & & & & 2 & 2 & 3 & 1 & 4 & & 3 & 15 & $5,10 \%$ \\
\hline Disclosure & & 1 & 1 & 3 & 5 & 2 & 1 & 1 & & & 14 & $4,76 \%$ \\
\hline Governança corporativa & & 1 & & 1 & 2 & 4 & 1 & 1 & & 4 & 14 & $4,76 \%$ \\
\hline Informação contábil & & 2 & 1 & & 1 & 1 & 2 & 2 & 2 & 3 & 14 & $4,76 \%$ \\
\hline Investimento & & & & & & 3 & 2 & 2 & 1 & 3 & 11 & $3,74 \%$ \\
\hline Auditoria & 1 & 1 & & 1 & 2 & & 1 & 1 & 1 & 2 & 10 & $3,40 \%$ \\
\hline Disclosure voluntário & & & 1 & 1 & 1 & & 2 & 1 & 2 & 2 & 10 & $3,40 \%$ \\
\hline Gestão pública & 1 & & 2 & 1 & 3 & 1 & 1 & 1 & & & 10 & $3,40 \%$ \\
\hline Disclosure ambiental & 1 & 1 & 2 & & 1 & 1 & & 1 & 1 & 1 & 9 & $3,06 \%$ \\
\hline Ativos biológicos & 1 & & & & 1 & & 1 & 2 & 1 & 2 & 8 & $2,72 \%$ \\
\hline Gestão tributária & & & & 1 & & & & 1 & 2 & 3 & 7 & $2,38 \%$ \\
\hline Valor Adicionado & & & & & & 2 & 1 & 3 & & 1 & 7 & $2,38 \%$ \\
\hline Ativos Intangíveis & & & & & 1 & 1 & & 2 & 1 & 1 & 6 & $2,04 \%$ \\
\hline Capital intelectual & 2 & & & 1 & 1 & 1 & & & 1 & & 6 & $2,04 \%$ \\
\hline Conservadorismo contábil & & & 1 & 1 & & & 2 & & 1 & & 5 & $1,70 \%$ \\
\hline Demonstrações contábeis & 1 & & 1 & 1 & & 1 & & & 1 & & 5 & $1,70 \%$ \\
\hline Análise financeira & & & 2 & & & & 1 & & & 1 & 4 & $1,36 \%$ \\
\hline Desempenho organizacional & & 1 & & & 1 & & 2 & & & & 4 & $1,36 \%$ \\
\hline Estrutura de propriedade & & & 3 & & & & & 1 & & & 4 & $1,36 \%$ \\
\hline Impairment & & & & 2 & 1 & & 1 & & & & 4 & $1,36 \%$ \\
\hline Ações & 1 & & & & & & 1 & & 1 & & 3 & $1,02 \%$ \\
\hline Book-tax diferences & & & & & & & & & 1 & 2 & 3 & $1,02 \%$ \\
\hline Contabilidade ambiental & 1 & & & 1 & & & & & 1 & & 3 & $1,02 \%$ \\
\hline Contabilidade pública & & & & 1 & & 1 & 1 & & & & 3 & $1,02 \%$ \\
\hline Disclosure socioambiental & & 1 & & & & 1 & & 1 & & & 3 & $1,02 \%$ \\
\hline Guidance & & & & & & & 2 & 1 & & & 3 & $1,02 \%$ \\
\hline Incentivos fiscais & & & & & & & 2 & & & 1 & 3 & $1,02 \%$ \\
\hline MDL's & 1 & & & & & 2 & & & & & 3 & $1,02 \%$ \\
\hline Pronunciamentos contábeis & & & & & 1 & 1 & 1 & & & & 3 & $1,02 \%$ \\
\hline Remuneração variável & & & & 1 & & 1 & & & & 1 & 3 & $1,02 \%$ \\
\hline SER & & & & & 1 & & & 1 & 1 & & 3 & $1,02 \%$ \\
\hline Cultura organizacional & & & & & & & & & & 2 & 2 & $0,68 \%$ \\
\hline Demonstração de fluxo de caixa & & & & 1 & & & & & & 1 & 2 & $0,68 \%$ \\
\hline Desempenho contábil & & & 2 & & & & & & & & 2 & $0,68 \%$ \\
\hline Desempenho financeiro & & & & & & & & & & 2 & 2 & $0,68 \%$ \\
\hline Disclosure obrigatório & & & & & & & & 1 & & 1 & $\begin{array}{c}2 \\
(\mathrm{CC}\end{array}$ & $\begin{array}{r}0,68 \% \\
\text { INUA) }\end{array}$ \\
\hline
\end{tabular}


(CONTINUAÇÃO)

\begin{tabular}{|c|c|c|c|c|c|c|c|c|c|c|c|c|c|}
\hline Disclosure social & 1 & & & & & 1 & & & & & & 2 & $0,68 \%$ \\
\hline Endividamento & & & & & & & 1 & & & & 1 & 2 & $0,68 \%$ \\
\hline Financial reporting & & & & 2 & & & & & & & & 2 & $0,68 \%$ \\
\hline Fraude contábil & & & & & 1 & & & 1 & & & & 2 & $0,68 \%$ \\
\hline Instrumentos financeiros & & & & & 1 & & & 1 & & & & 2 & $0,68 \%$ \\
\hline Lobbying & & & & & & & 1 & & & & 1 & 2 & $0,68 \%$ \\
\hline Modelo Fleuriet & & & & & & & & & & & 2 & 2 & $0,68 \%$ \\
\hline NBC & & & 1 & & 1 & & & & & & & 2 & $0,68 \%$ \\
\hline Preço de transferência & & & & & & & & & & 1 & 1 & 2 & $0,68 \%$ \\
\hline Responsabilidade socioambiental & & 1 & & & 1 & & & & & & & 2 & $0,68 \%$ \\
\hline Sustentabilidade empresarial & & 1 & & & & & 1 & & & & & 2 & $0,68 \%$ \\
\hline Valor justo & & & & & & 1 & 1 & & & & & 2 & $0,68 \%$ \\
\hline Value relevance & & & & 1 & & 1 & & & & & & 2 & $0,68 \%$ \\
\hline Accountability & & & & & & & & 1 & & & & 1 & $0,34 \%$ \\
\hline Accruals & & & & & & & 1 & & & & & 1 & $0,34 \%$ \\
\hline Asset revaluations & & & & & & & & & & & 1 & 1 & $0,34 \%$ \\
\hline Ativos fiscais & & & & & & & & 1 & & & & 1 & $0,34 \%$ \\
\hline Avaliação de empresas & & 1 & & & & & & & & & & 1 & $0,34 \%$ \\
\hline Board interlocking & & & & & & & & & & 1 & & 1 & $0,34 \%$ \\
\hline Book-to-market & & & & & & & & & & & 1 & 1 & $0,34 \%$ \\
\hline Contabilidade financeira & & & 1 & & & & & & & & & 1 & $0,34 \%$ \\
\hline Contabilidade governamental & & 1 & & & & & & & & & & 1 & $0,34 \%$ \\
\hline Controle interno & & & & & 1 & & & & & & & 1 & $0,34 \%$ \\
\hline Custos & & 1 & & & & & & & & & & 1 & $0,34 \%$ \\
\hline Desempenho econômico-financeiro & & & & & & & & 1 & & & & 1 & $0,34 \%$ \\
\hline Dividendos & & 1 & & & & & & & & & & 1 & $0,34 \%$ \\
\hline Ética & & & 1 & & & & & & & & & 1 & $0,34 \%$ \\
\hline Finanças comportamentais & & & & 1 & & & & & & & & 1 & $0,34 \%$ \\
\hline Gestão ambiental & & & & & & & & & & 1 & & 1 & $0,34 \%$ \\
\hline Gestão de risco & & & & & & & & & & & 1 & 1 & $0,34 \%$ \\
\hline Goodwill & & & & & & & & & & 1 & & 1 & $0,34 \%$ \\
\hline Hedge Accounting & & & 1 & & & & & & & & & 1 & $0,34 \%$ \\
\hline Heritage assets & & & & & & & & & & 1 & & 1 & $0,34 \%$ \\
\hline Imobilização & & & & & & & 1 & & & & & 1 & $0,34 \%$ \\
\hline Inovação tecnológica & & & & & & & & & & 1 & & 1 & $0,34 \%$ \\
\hline Insider trading & & & & & & & & & & 1 & & 1 & $0,34 \%$ \\
\hline Instituição financeira & & & & & & 1 & & & & & & 1 & $0,34 \%$ \\
\hline Internacionalização & & & & & & & & & & & 1 & 1 & $0,34 \%$ \\
\hline Joint Venture & & & & & & & & & & 1 & & 1 & $0,34 \%$ \\
\hline Leasing & & & & & & & 1 & & & & & 1 & $0,34 \%$ \\
\hline LRF & & & & & 1 & & & & & & & 1 & $0,34 \%$ \\
\hline Lei Sarbanes-Oxley & & & 1 & & & & & & & & & 1 & $0,34 \%$ \\
\hline Logística reversa & & & & & & & & 1 & & & & 1 & $0,34 \%$ \\
\hline Lucro & & & 1 & & & & & & & & & 1 & $0,34 \%$ \\
\hline Medidas de desempenho & & & & & & & 1 & & & & & 1 & $0,34 \%$ \\
\hline Mercado de capitais & & & & & & & & 1 & & & & 1 & $0,34 \%$ \\
\hline Mercado financeiro & 1 & & & & & & & & & & & 1 & $0,34 \%$ \\
\hline Modelo de BASU & & & 1 & & & & & & & & & 1 & $0,34 \%$ \\
\hline Parceria público-privada (PPP) & 1 & & & & & & & & & & & 1 & $0,34 \%$ \\
\hline Perícia contábil & & & & & & & & 1 & & & & 1 & $0,34 \%$ \\
\hline Plano de contas & & & & 1 & & & & & & & & 1 & $0,34 \%$ \\
\hline Recursos humanos & & 1 & & & & & & & & & & 1 & $0,34 \%$ \\
\hline Regime de competência & & & & & & & 1 & & & & & 1 & $0,34 \%$ \\
\hline Teoria da contabilidade & 1 & & & & & & & & & & & 1 & $0,34 \%$ \\
\hline Turnover & & & & & & & & & & 1 & & 1 & $0,34 \%$ \\
\hline Total & 16 & 17 & 24 & 24 & 32 & 32 & 36 & 536 & & 29 & 48 & 294 & $100,00 \%$ \\
\hline
\end{tabular}


Conforme a Tabela 1, o tema mais publicado foi Gerenciamento de Resultados, com 16 artigos. É tema de pesquisa razoavelmente vasto nos âmbitos nacional e internacional, influenciando o surgimento de várias definições, uma das mais estudadas (CARDOSO; SOUZA; DANTAS, 2015) baseando-se na ótica do disclosure das informações contábeis (MACHADO; BENETTI; BEZERRA, 2011). Recebe, assim, atenção dentro e fora da academia (BAPTISTA, 2009), sobretudo nos mercados dos Estados Unidos, Reino Unido, Austrália, Canadá, França e Finlândia (ERFURTH; BEZERRA, 2013). Ressalta-se que a qualidade das informações contábeis e o gerenciamento de resultados se intensificaram, na Europa e no Brasil, após a adoção de normas internacionais de contabilidade (COELHO; NIYAMA; RODRIGUES, 2011; CARDOSO; SOUZA; DANTAS, 2015).

O tema Normas Internacionais de Contabilidade foi o segundo mais divulgado, com 15 publicações. Seu destaque deve-se ao fato de que seu processo de convergência trouxe mudanças para o disclosure da informação contábil (GONÇALVES et al., 2014). Em outras palavras, o processo de convergência das normas internacionais de contabilidade ocasiona benefícios às organizações, como, por exemplo, mais harmonização e disclosure, mitigando assim os conflitos de agência e, consequentemente, a assimetria informacional (REINA; REINA; SILVA, 2014).

As temáticas Disclosure, Governança Corporativa e Informação contábil vêm a seguir, todas com 14 estudos publicados. O realce desses temas, nesta pesquisa, é em decorrência de sua intrínseca relação (MALACRIDA; YAMAMOTO, 2006) com a contabilidade (GABRIEL, 2011), em especial com contabilidade para usuários externos (MOURA et al., 2011). Diante disso, podese entender e compreender que um dos principais princípios que balizam e regem as boas práticas de governança corporativa é o disclosure, que consiste na divulgação precisa e transparente das informações contábeis pertinentes ao desenvolvimento e crescimento dos negócios (PONTE; OLIVEIRA, 2004), obtendo a posteriori retorno nos investimentos (MALACRIDA; YAMAMOTO, 2006).

A temática Investimento vem a seguir com 11 divulgações. E, com 10 publicações, aparecem as temáticas: Auditoria, Disclosure Voluntário e Gestão Pública. No que tange à auditoria, é considerada de importância salutar e componente-chave como mecanismo de governança corporativa, possuindo 
particular apreciação dos reguladores, profissionais, investidores, enfim, dos stakeholders em geral (MENDONÇA et al., 2010). Tal mecanismo é o comitê de auditoria, um órgão administrado pelo conselho de administração da empresa para auxiliar a organização na governança corporativa e, consequentemente, na qualidade e no disclosure das informações contábeis divulgadas (CUNHA; PLETSCH; SILVA, 2015).

O disclosure voluntário excede o que é aconselhado pela lei e representa uma alternativa livre por parte dos gestores para divulgar as informações adicionais para o processo decisório dos stakeholders na tomada de decisão (MURCIA; SANTOS, 2012). Neste contexto, salientase que "em muitos países, assim como no Brasil, o disclosure ambiental é voluntário e algumas teorias tentam explicar os motivos que levam as empresas à divulgação dessas informações" (CORREA; GONÇALVES; MORAES, 2015, p. 139). O disclosure ambiental surge também como um dos temas mais publicados, com nove artigos.

Em suma, os 10 primeiros temas evidenciados na Tabela 1 foram responsáveis pela publicação de 123 artigos, o que equivale a $42 \%$ do montante de 294 pesquisas divulgadas. 40 temas foram divulgados entre duas e oito vezes, sendo responsáveis assim por publicar 129 papers equivalendo a $44 \%$ do total das investigações. E 42 temas foram abordados somente uma vez cada, o que perfaz $14 \%$ da soma dos trabalhos identificados neste estudo. Os temas pouco abordados criam uma oportunidade de geração de novos estudos por parte de pesquisadores seniores e/ou iniciantes.

A heterogeneidade e a diversidade de temas evidenciados nesta seção mostra a preocupação do congresso ANPCONT em manifestar, disseminar e socializar informações e conhecimentos diversos sobre contabilidade para usuários externos. Com isso, propiciam-se oportunidades para o surgimento de novos estudos, temas, autores e grupos de trabalho, impactando diretamente uma amplitude maior de IESs. Estas, por meio de seus próprios pesquisadores, possibilitam o entrelaçamento e conexão de ideias e insights, que cooperam, por sua vez, para o surgimento de hipóteses e modelos.

\section{CONSIDERAÇÕES FINAIS}

O objetivo deste estudo foi investigar o perfil e o comportamento das publicações relacionadas à área temática contabilidade para usuários externos divulgada no congresso ANPCONT de 2007 a 2016. Constatou-se que os autores 
Fernando Dal-Ri Murcia, Marcelo Alvaro da Silva Macedo e Roberto Carlos Klann foram os mais produtivos, representando algumas das IESs que ficaram em ênfase nesta pesquisa. Ainda no tocante às características dos pesquisadores, ressaltase que a formação de parcerias é fundamental para o desenvolvimento de pesquisas científicas (CRUZ et al., 2011), tal como corroborado por investigações análogas (BARBOSA; BARROS, 2010; CRUZ ET AL., 2011; MATOS ET AL.; 2012)

As IESs mais profícuas foram USP, Fucape, UFPB, FURB, UFC e UFRJ. Dentre elas, as que possuem maior centralidade de grau (MENDES-DASILVA; ONUSIC; GIGLIO, 2013) são USP, UFPB, Unisinos e UFRJ. E, destas quatro, as três primeiras se destacam como as de centralidade de intermediação maior (CRUZ et al., 2011). Tal resultado mostra a envergadura, importância e representatividade dessas instituições na produção acadêmica de temas relacionados à área temática aqui investigada.

Os temas mais divulgados foram: gerenciamento de resultados, normas internacionais de contabilidade, disclosure, governança corporativa, informação contábil, investimento, auditoria, disclosure voluntário, gestão pública e disclosure ambiental. Além desses 10 temas em destaque, outros 82 foram publicados em 10 anos de investigação da produção cientifica, o que nos faz entender, compreender e constatar a diversidade de assuntos relacionados com contabilidade para usuários externos.

As informações manifestadas neste estudo contribuem para minimizar gaps que possam ter ocorrido pela falta ou omissão de estudos correlatos a este na literatura acadêmica nacional. Realça-se, assim, que os conhecimentos contemplados neste trabalho também contribuem para fazer avançar o estado da arte em Contabilidade para Usuários Externos ajudando em seu aperfeiçoamento, difusão e socialização na academia, não somente por ocasião de eventos, mas também publicações em revistas científicas.

\section{Este estudo restringiu-se aos} congressos da ANPCONT, daí se sugerir, para estudos futuros, fazer uma comparação da área temática em outros congressos, em âmbito nacional e internacional, ampliando ainda mais as informações e conhecimentos aqui evidenciados. Outra sugestão é investigar de maneira mais ampla os temas identificados e abordados nesta pesquisa, a fim de que se possa compreender melhor suas nuances no bojo da área temática investigada. Sugere-se, ainda, contemplar mais indicadores bibliométricos e 
sociométricos, influenciando com isso uma

maior diversidade de informações e saberes no tocante à área temática analisada. 


\section{REFERÊNCIAS}

AMARAL, M.R. do et al. Perfil dos autores na produção científica em mercado financeiro de crédito e de capitais nos congressos USP de controladoria e contabilidade e congresso ANPCONT. Revista Evidenciação Contábil \& Finanças, v. 2, n. 2, p. 55-68, 2014.

ANJOS, C.E.L. dos et al. Produção científica na área de perícia contábil: um estudo bibliométrico em periódicos nacionais. Revista de Contabilidade da UFBA, v. 9, n. 3, 2015.

ANPCONT - Associação Nacional de Programas de Pós-Graduação em Ciências Contábeis. XI Congresso ANPCONT. Disponível em: <http://congressos.anpcont.org.br/xi/>. Acesso em: 06 out. 2017.

ASSUNÇÃO, A.B. de A. Comportamento dos contadores diante de uma visão otimista ou pessimista de um ambiente econômico simulado. Dissertação (Mestrado em Ciências Contábeis), Brasília: UnB, 2011, 76 pg.

BALESTRIN, A.; VERSCHOORE, J. R.; REYES JUNIOR, E. O campo de estudo sobre redes de cooperação interorganizacional no Brasil. Revista de Administração Contemporânea, v. 14, n. 3, p. 458-477, 2010.

BAPTISTA, E.M.B. Ganhos em transparência versus novos instrumentos de manipulação: o paradoxo das modificações trazidas pela lei $\mathrm{n}^{\mathbf{o}}$ 11.638. Revista de Administração de Empresas, v. 49, n. 2, p. 234-239, 2009.

BARBOSA, G. de C.; BARROS, F. de O. Perfil dos autores na produção científica em contabilidade: o caso do congresso USP de controladoria e contabilidade e do congresso ANPCONT. Enfoque: Reflexão Contábil, v. 29, n. 3, p. 22-33, 2010.

BARBOSA, J. da S.; KLEIN, L.; COLAUTO, R. D.; BEUREN, I. M. Tridimensionalidade da linguagem contábil em publicações de periódicos científicos brasileiros. Revista Universo Contábil, v. 10, n. 3, p. 44-64, 2014.

BEUREN, I. M.; SCHLINDWEIN, A. C.; PASQUAL, D. L. Abordagem da controladoria em trabalhos publicados no Enanpad e no Congresso USP de controladoria e contabilidade de 2001 a 2006. Revista Contabilidade \& Finanças, v. 18, n. 45, p. 22-37, 2007.

BONFIM, M. D. Aspectos gerais da produção científica dos programas stricto sensu em contabilidade no Brasil: um estudo baseado nas teses e dissertações. Dissertação (Mestrado em Ciências Contábeis, Ribeirão Preto: USP, 2013, 233 pg. 
BORGES, T.N.; FARIA, A.C. de; GIL, A. de L. Ensaio teórico sobre os fatores críticos de sucesso e pontos de falha do processo de gestão dos mestrandos em contabilidade: a ótica da metodologia DEQ. Revista de Educação e Pesquisa em Contabilidade, v. 1, n. 3, 2007.

BRANDÃO, P. de M.; BALDI, M.; ALBAN, M. (Des)Centralização da gestão pública do turismo brasileiro: análise da participação dos atores privados no Conselho Nacional de Turismo. Tourism \& Management Studies, v. 10, n. Edição Especial, 193-199, 2014.

BRIZOLLA, M.M.B.; CHIARELLO, T.C.; LAVARDA, C.E.F. Abordagem a respeito da controladoria e contabilidade gerencial: um estudo das redes sociais publicado em periódicos internacionais. Revista de Gestão e Contabilidade da UFPI, v. 1, n. 1, p. 119-140, 2014.

BRUGNI, T.V. et al. Influência de dividendos sobre a informatividade dos lucros: evidências empíricas na BM\&FBovespa. Revista Universo Contábil, v. 8, n. 3, p. 82-99, 2012.

BRUNELLI, M. DE Q.; MACEDO-SOARES, T.D.L. van A. de; ZOUAIN, D.M.; BORGES, A.P. Scientific research in tourism: review of the literature from 2005 to 2009. Revista de Administração Pública, v. 44, n. 5, p. 1225-1240, 2010.

CARDOSO, R.L.; MENDONÇA NETO, O.R. de; RICCIO, E.L.; SAKATA, M.C.G. Pesquisa científica em contabilidade entre 1990 e 2003. Revista de Administração de Empresas, v. 45, n. 2, p. 34-45, 2005.

CARDOSO, R.L.; PEREIRA, C.A.; GUERREIRO, R. Perfil das pesquisas em contabilidade de custos apresentadas no EnANPAD no período de 1998 a 2003. Revista de Administração Contemporânea, v. 11, n. 3, p. 177-198, 2007.

CARDOSO, R. L.; SOUZA, F.S.R.N. de; DANTAS, M.M. Impactos da adoção do IFRS na acumulação discricionária e na pesquisa em gerenciamento de resultados no Brasil. Revista Universo Contábil, v. 11, n. 2, p. 65-84, 2015.

COELHO, A.C.; SOUTES, D.O.; MARTINS, G. de A. Abordagens metodológicas na área "contabilidade para usuários externos" - Enanpad: 2005-2006. Revista de Educação e Pesquisa em Contabilidade, v. 4, n. 1, p. 18-37, 2010.

COELHO, C.M.P.; NIYAMA, J.K.; RODRIGUES, J.M. Análise da qualidade da informação contábil frente a implementação dos IFRS: uma pesquisa baseada nos periódicos internacionais (1999 a 2010). Sociedade, Contabilidade e Gestão, v. 6, n. 2, p. 7-20, 2011. 
CORREA, J.C.; GONÇALVES, M.N.; MORAES, R. de O. Disclosure ambiental das companhias do setor de petróleo, gás e biocombustíveis listadas na bm\&fbovespa: uma análise à luz da teoria da legitimidade. Revista de Gestão Ambiental e Sustentabilidade, v. 4, n. 3. p. 139-154, 2015.

COSENZA, J.P. et al. Análise das características e similaridades presentes na produção científica dos congressos ANPCONT 2007-2014. Revista Contemporânea de Contabilidade, v. 13, n. 28, p. 19-56, 2016.

COSTA, F.; MARTINS, G. de A. Características epistemológicas de publicações científicas em Contabilidade: evidências de um cenário produtivista. Revista Contemporânea de Contabilidade, v. 13, n. 29, p. 33-68, 2016.

CRUZ, A.P.C. da et al. Perfil das redes de cooperação científica: congresso USP de controladoria e contabilidade - 2001 a 2009. Revista Contabilidade \& Finanças, v. 22, n. 55, p. 64-87, 2011.

CRUZ, C.F. da; FERREIRA, A.C. de S.; SZUSTER, N. Estrutura conceitual da contabilidade no Brasil: percepção dos docentes dos programas de pós- graduação stricto sensu em ciências contábeis. Pensar Contábil, v. 13, n. 50, p. 53-63, 2011.

CUNHA, P.R. da; PLETSCH, C.S.; SILVA, A. da. Relação entre as características da empresa, do comitê de auditoria e do auditor independente com o prazo de publicação das demonstrações financeiras. Revista de Educação e Pesquisa em Contabilidade, v.9, 2015.

DAVEL, E.; ALCADIPANI, R. Estudos críticos em administração: a produção científica brasileira nos anos 1990. Revista de Administração de Empresas, v. 43, n. 4, 2003.

DIAS, W. de O.; NETO, J.E.B.; BARBOSA, R.R. Design e qualidade da informação nos websites dos programas brasileiros de pós-graduação em contabilidade. Revista de Informação Contábil, v. 4, n. 4, p. 1-22, 2010.

ERFURTH, A.E.; BEZERRA, F.A. Gerenciamento de resultados nos diferentes níveis de governança corporativa. Revista BASE da Unisinos, v. 10, n. 1, p. 32-42, 2013.

ESTRELlA, A.; BATAGLIA, W. A influência da rede de alianças no crescimento das empresas de biotecnologia de saúde humana na indústria brasileira. Organizações \& Sociedade, v. 20, n. 65, p. 321-340, 2013. 
FARIA, J.A. de; GOMES, S.M. da S.; DIAS FILHO, J.M.; ALBUQUERQUE, V. A Assimetria da informação na elaboração do orçamento: uma análise da produção científica nos periódicos internacionais entre 2005 e 2009. Revista Contabilidade Vista \& Revista, v. 22, n. 2, p. 43-65, 2011.

FREZATTI, F.; AGUIAR, A.B. de; GUERREIRO, R. Diferenciações entre a contabilidade financeira e a contabilidade gerencial: uma pesquisa empírica a partir de pesquisadores de vários países. Revista Contabilidade \& Finanças, n. 44, p. 9-22, 2007.

FREZATTI, F. Comunicações informações editorias 2016. Revista Contabilidade \& Finanças, v. 28, n. 73, p. 148-165, 2017.

GABRIEL, F. Impacto da adesão às práticas recomendadas de governança corporativa no índice de qualidade da informação contábil. Tese (Doutorado em Ciências Contábeis), São Paulo: FEA/USP, 2011, 130 pg.

GOMES, C.H.P.; CAVALCANTE, P.S.; LINS, W.C.B. Análise de redes de colaboração científica dos docentes do programa de pós-graduação em educação matemática e tecnológica da Universidade Federal de Pernambuco. Em Teia, v. 7, n. 2, p. 1-25, 2016.

GONÇALVES, J.C. et al. Análise do impacto do processo de convergência às normas internacionais de contabilidade no brasil: um estudo com base na relevância da informação contábil. Revista Universo Contábil, v. 10, n. 3, p. 25-43, 2014.

LEAL, R.P.C.; ALMEIDA, V. de S.E.; BORTOLON, P.M. Produção científica brasileira em finanças no período 2000-2010. Revista de Administração de Empresas, v. 53, 2013.

LIMA, F.D.C.; DINIZ, J.R.; SILVA, D.M. da. Perfil de Produção científica em contabilidade: um comparativo entre os periódicos Contabilidade Vista \& Revista e Universo Contábil, no período de 2006 a 2010. RACE, v. 12, n. 2, p. 607-640, 2013.

MACHADO, D.; BENETTI, J.; BEZERRA, F. Análise da produção científica sobre «earnings management» em periódicos brasileiros e internacionais de contabilidade. Revista de Gestão dos Países de Língua Portuguesa, v. 10, n. 4, p. 50-66, 2011.

MACHADO, D.P. et al. Incentivo à pesquisa científica durante a graduação em ciências contábeis: um estudo nas universidades do estado do Rio Grande do Sul. Revista de Informação Contábil, v. 3, n. 2, p. 37-60, 2009.

MACHADO JUNIOR, C.; SOUZA, M.T.S. de; PARISOTTO, I.R. dos S. Institucionalização 
do conhecimento em sustentabilidade ambiental pelos programas de pós-gradução stricto sensu em administração. Revista de Administração Contemporânea, v. 18, n. 6, p. 854-873, 2014.

MALACRIDA, M.J.C.; YAMAMOTO, M.M. Governança corporativa: nível de evidenciação das informações e sua relação com a volatilidade das ações do Ibovespa. Revista Contabilidade \& Finanças, v. 17, n. Edição Especial, p. 65-79, 2006.

MARTINS, O.S.; LUCENA, W.G.L. Produtivismo acadêmico: as práticas dos docentes dos programas de pós-graduação em contabilidade. ASAA, v. 7, n. 1, p. 66-96, 2014.

MATOS, E.B.S. de et al. Congresso ANPCONT: análise bibliométrica descritiva e avaliativa dos artigos publicados de 2007 a 2011. Enfoque: Reflexão Contábil, v. 31, n. 3, 2012.

MELlO, C.M. de; CRUBELlATE, J.M.; ROSSONI, L. Dinâmica de relacionamento e prováveis respostas estratégicas de programas brasileiros de pós-graduação em administração à avaliação da CAPES: proposições institucionais a partir da análise de redes de co-autorias.

Revista de Administração Contemporânea, v. 14, n. 3, p. 434-457, 2010.

MENDES-DA-SILVA, W.; ONUSIC, L.M.; GIGLIO, E.M. Rede de Pesquisadores de Finanças no Brasil: Um Mundo Pequeno Feito por Poucos. Revista de Administração Contemporânea, v. 17, n. 6, p. 739-763, 2013.

MENDONÇA, M.M. de et al. O impacto da Lei Sarbanes-Oxley (SOX) na qualidade do lucro das empresas brasileiras que emitiram ADRs. Revista Contabilidade \& Finanças, v. 21, n. 52, p. 1-24, 2010.

MENDONÇA NETO, O.R. de; RICCIO, E.L.; SAKATA, C.G. Dez anos de pesquisa contábil no Brasil: análise dos trabalhos apresentados nos ENANPADs de 1996 a 2005. Revista de Administração de Empresas, v. 49, n. 1, p. 62-73, 2009.

MORÁS, V.R.; KLANN, R.C. Contabilidade do setor público: um estudo das redes sociais publicadas em periódicos internacionais. RACE, v. 15, n. 3, p. 1143-1168, 2016.

MOURA, G. D. de et al. Contabilidade e finanças: análise da plataforma teórica dos congressos ANPCONT e USP no período de 2007 a 2009. ConTexto, v. 11, n. 19, p. 7-19, 2011.

MURCIA, F.D.R.; SANTOS, A. dos. Discretionary-based disclosure: evidence from the brazilian market. Brazilian Administration Review, v. 9, n. 1, p. 88-109, 2012. 
NASCIMENTO, A.R. do; JUNQUEIRA, E.; MARTINS, G. de A. Pesquisa acadêmica em contabilidade gerencial no Brasil: análise e reflexões sobre teorias, metodologias e paradigmas. Revista de Administração Contemporânea, v. 14, n. 6, p. 1113-1133, 2010.

NASCIMENTO, S. do; BEUREN, I.M. Redes sociais na produção científica dos programas de pósgraduação de ciências contábeis do Brasil. Revista de Administração Contemporânea, v. 15, n. 1, p. 47-66, 2011.

NORONHA, A.P.P. et al. (2006). Análise de teses e dissertações em orientação profissional. Revista Brasileira de Orientação Profissional, v. 7, n. 2, p. 1-10, 2006.

PINHEIRO, L.V.; SILVA, E.L. da. As redes cognitivas na ciência da informação brasileira: um estudo nos artigos científicos publicados nos periódicos da área. Ciência da Informação, v. 37, n. 3, p. 38-50, 2008.

PONTE, V.M.R.; OLIVEIRA, M.C. A prática da evidenciação de informações avançadas e não obrigatórias nas demonstrações contábeis das empresas brasileiras. Revista Contabilidade \& Finanças, v. 15, n. 36, p. 7-20, 2004.

RAVELLI, A.P.X. et al. A produção do conhecimento em enfermagem e envelhecimento: estudo bibliométrico. Texto Contexto - Enfermagem, v. 18, n. 3, p. 506-12, 2009.

REINA, D.R.M.; REINA, D.; SILVA, S.F. da. Comparabilidade da informação contábil em empresas brasileiras após a adoção das normas internacionais de contabilidade. Revista Contemporânea de Contabilidade, v. 11, n. 23, p. 77-94, 2014.

RIBEIRO, H.C.M. Produção acadêmica dos artigos publicados em revistas científicas nacionais disponibilizadas na Base Atena sobre o tema gestão de riscos de 2000 a 2015. Revista Evidenciação Contábil \& Finanças, v. 5, n. 1, p. 75-93, 2017.

Teoria dos stakeholders: um estudo bibliométrico de sua produção acadêmica divulgada nos periódicos nacionais de 1999 a 2013. Revista Contemporânea de Economia e Gestão, v. 14, n. 1, p. 163-192, 2016.

; RÖDER, E. dos S. F.; SILVA, E.L. da. Agricultura familiar e as teses de doutorado no Brasil. TransInformação, v. 25, n. 2, p. 111-126, 2013.

RIBEIRO, H.C.M.; SANTOS, M.C. dos. Perfil e evolução da produção científica do tema 
governança corporativa nos periódicos Qualis/Capes nacionais: uma análise bibliométrica e de redes sociais. Contabilidade, Gestão e Governança, v. 18, n. 3, p. 04-27, 2015.

SANTOS, R.N.M. dos. Produção científica: por que medir? O que medir? Revista Digital de Biblioteconomia e Ciência da Informação, v . 1, n. 1, p. 22-38, 2003.

SANTOS, V. dos et al. Folga orçamentária: características das publicações em periódicos internacionais. Revista Contabilidade Vista e Revista, v. 27, n. 1, p. 88-110, 2016.

SANTOS, V. dos; KLANN, R.C.; RAUSCH, R.B. Perfil das dissertações do mestrado em Ciências Contábeis da USP e FURB. Contabilidade, Gestão e Governança, v. 14, 2011.

SILVA, A.C. da; WANDERLEY, C.A.N.; SANTOS, R. dos. Utilização de ferramentas estatísticas em artigos sobre contabilidade financeira - um estudo quantitativo em três congressos realizados no país. Revista Contemporânea de Contabilidade, v. 1, n. 14, 2010.

SILVA, M.Z. da; BEUREN, I.M. Contabilidade gerencial em hospitais: análise bibliométrica de artigos publicados no período 1950 a 2011. Revista Alcance, v. 22, 2015.

SOUZA, F.C. de et al. Análise das IES da área de ciências contábeis e de seus pesquisadores por meio de sua produção científica. Revista Contabilidade Vista e Revista, v. 19, 2008.

SOUZA, M.J.P. de; FERREIRA, A.L.; HANLEY, A. et al. A quantitative analysis of the academic economic literature regarding the Brazilian Development Bank (BNDES). EconomiA, v. 16, n. 2, p. 157-175, 2015.

SOUZA, P. A. R. de; FARINA, M. C.; COSTA, C. de O. et al. Relações Sociais no setor de cama \& café em parintins na amazônia: uma perspectiva com base nas análises de redes sociais. Revista Brasileira de Pesquisa em Turismo, v. 8, n. 1, p. 145-160, 2014.

WALTER, S.A.; BACHL, T.M.; BARBOSA, F. Estratégia como prática: análise longitudinal por meio de bibliometria e sociometria. Rebrae, v. 5, n. 3, p. 307-323, 2012. 